\title{
Central components of the renin-angiotensin system
}

\author{
J. HAYDEN AND MARGARET A. TARGETT
}

The Nicholas Research Institute, Slough, Buckinghamshire

\section{Summary}

1. Re-establishment of renal blood flow after total renal ischaemia of $4 \mathrm{~h}$ duration causes a pressor response in pentobarbitone anaesthetized rats and cats.

2. The pressor response is related to the release of renin from the ischaemic kidney.

3. Spinal section at any cervical level or stellate ganglionectomy abolishes the pressor response but spinal section caudad to the thorax or vagotomy and treatment with hexamethonium have no effect.

4. Spinal section and stellate ganglionectomy interfere with the release of renin and with the pressor response to angiotensin.

\section{Introduction}

The pressor activity of angiotensin II was for many years considered to be primarily the result of its direct constrictor action on arteriolar smooth muscle (Page \& Bumpus, 1961). More recently various authors have described nervously mediated effects of angiotensin II either peripherally (McCubbin \& Page, 1963 ; Feldberg \& Lewis, 1964 ; Benelli, Della Bella \& Gandini, 1964 ; Laverty, 1963 ; Distler, Liebau \& Wolff, 1965 ; Lewis \& Reit, 1965 ; Aiken \& Reit, 1968) or via a central mechanism (Buckley, Bickerton, Halliday \& Kato, 1963; Ferrario, Dickinson, Gildenberg \& McCubbin, 1969 ; Scroop \& Lowe, 1968 ; Scroop \& Whelan, 1966).

Various hypotheses have been postulated for the mechanism of release of renin (Lee, 1969) including the so-called 'sympathetic nervous theory'. Most studies of this mechanism have been concerned with peripheral aspects and not with central modulation. The experiments described below show that central components are involved in the release of renin and in the pressor responses to angiotensin II formed subsequently.

A simple preparation for demonstrating the release of pressor substances from an ischaemic kidney in dogs upon re-establishment of the circulation was described by Taquini (1938). This work was subsequently confirmed in rats, cats, and dogs by Lewis, Leo \& Prinzmetal (1941) who described the experimental procedure in detail, but were not able to show a similar effect in rabbits (Prinzmetal, Lewis, Taggart, Wilkins \& Drury, 1940). The pressor substance in perfusates of ischaemic kidneys was presumed to be renin for the following reasons: (i) it showed tachyphylaxis, (ii) the configuration of the pressor response was similar to that given by an injection of renin, (iii) the pressor activity was destroyed by boiling the perfusates, (iv) when incubated with plasma the perfusate yielded a heat stable pressor substance, (v) less pressor substance could be obtained by extraction of the ischaemic kidney 
after re-establishment of the circulation, (vi) the pressor effect was not antagonized either by cocaine or by the adrenolytic compound $933 \mathrm{~F}$.

We have confirmed the findings of Prinzmetal and his colleagues and have investigated some aspects of the pressor response in greater detail.

\section{Methods}

Most experiments were carried out in male rats of the CFE or CFY strain weighing between $200 \mathrm{~g}$ and $300 \mathrm{~g}$. In some experiments, female cats weighing $2-3.5 \mathrm{~kg}$ were used. The animals were anaesthetized with ether and the left kidney was exposed through a lateral incision. The renal pedicle was freed from fat and connective tissue. The blood vessels were separated from the ureter and occluded with a $2.5 \mathrm{~cm}$ Dieffenbach clip with its jaws covered with soft PVC tubing. The wound was then closed and the animal allowed to recover. About $3 \frac{1}{2} \mathrm{~h}$ later the animals were anaesthetized with sodium pentobarbitone, $50 \mathrm{mg} / \mathrm{kg}$ body weight (rats) or $30-38 \mathrm{mg} / \mathrm{kg}$ body weight (cats). The systemic blood pressure $(1 \mathrm{~mm}$ $\mathrm{Hg} \equiv 1.333$ mbar) was recorded from either a carotid or a femoral artery using a Devices/C.E.C. blood pressure transducer and in some experiments the heart rate was derived from the electrocardiogram by a Devices ratemeter. Recording was by means of a Devices M8 recorder. The abdominal wound was re-opened and the clip located. The blood pressure was allowed to attain a steady level before the clip was removed approximately $4 \mathrm{~h}$ after its application.

Section of the spinal cord was carried out from the dorsal aspect, the remainder of the cord being left intact. In those experiments in which the cord was cut between the skull and the atlas, the brain was destroyed with a probe but in all other experiments the brain was left intact. The stellate ganglia were removed via a ventral approach through the thorax. Where necessary respiration was maintained with a 'Palmer' miniature 'Ideal' respiration pump.

The presence of circulating vaso-active substances was detected by means of a series of isolated organs superfused with either Krebs solution or blood (Regoli \& Vane, 1964 ; Vane, 1969). Rat stomach strip, either guinea-pig ileum or chick rectum and rat colon were used in descending order. In the initial experiments blood samples were removed from the renal vein into clean heparinized $1 \mathrm{ml}$ tuberculin syringes but in later experiments the blood was monitored continuously, being withdrawn from a carotid artery and returned to the jugular vein by means of a roller pump.

A simple check that the renal circulation had been re-established was made by injecting $0.1 \mathrm{ml}$ of a $0 \cdot 1 \%$ solution of adrenaline tartrate into the kidney pulp at the end of the experiment. If the renal circulation had been re-established this produced a marked response on blood pressure and heart rate.

In those experiments in which blood was superfused continuously, the contralateral kidney was removed to ensure that no renin could be released from this source as a result of blood volume changes upon establishment of the extracorporeal circulation.

\section{Drugs}

The drugs used were adrenaline tartrate (Evans Medical Ltd), atropine sulphate (B.D.H. Ltd), cyproheptadine hydrochloride (Merck, Sharpe \& Dohme Ltd), 
mepyramine maleate (May \& Baker Ltd), val-5-angiotensin II amide (Ciba Laboratories Ltd). Renin was prepared from rat kidneys by the method of Haas, Goldblatt, Gipson \& Lewis (1966).

\section{Results}

\section{Pressor response to re-establishment of renal circulation}

The pressor effect resulting from release of the clip on the renal pedicle was confirmed in both rats and cats (Fig. 1). The response occurred only if the renal artery was occluded and whether or not the renal vein was also occluded. The response did not occur if the renal vein but not the renal artery was occluded. The mean magnitude of the pressor responses in rats was $48 \mathrm{mmHg}$ S.E. $\pm 2.52(n=15)$ persisting for 15-30 minutes. In cats the pressor response was usually smaller than in rats. The heart rate usually fell slightly when the clip was released and increased
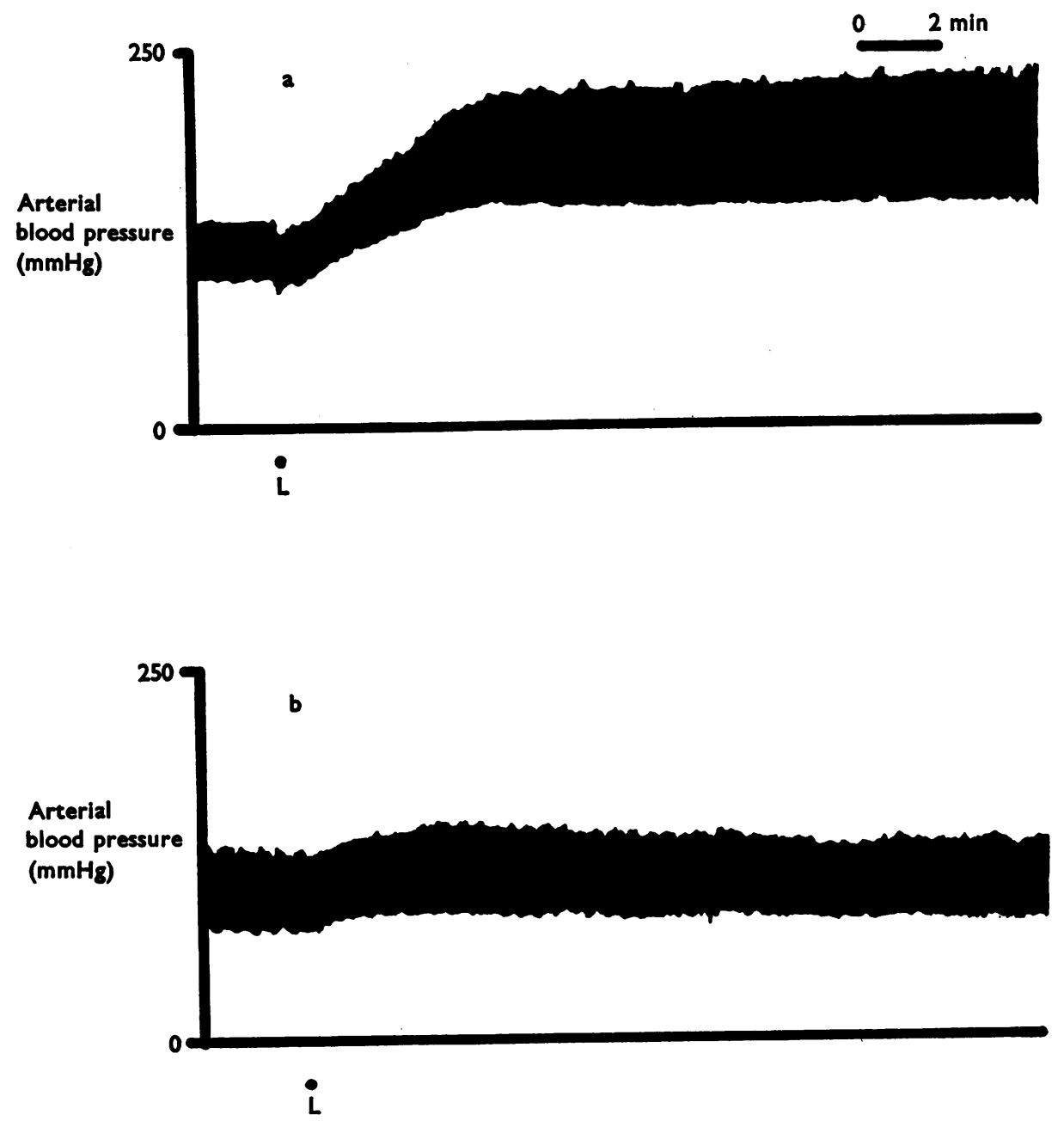

FIG. 1. Pressor effects of release of left renal pedicle clip (L) in pentobarbitone anaesthetized rat (a) and cat (b). 
again when the blood pressure fell. The response closely resembled that produced by a large intravenous injection of rat renin (Fig. 4). When the blood pressure had returned to near pre-release values the preparation then showed tachyphylaxis to the release of a similar clip applied to the contralateral kidney and to intravenous injections of val-5-angiotensin II amide (Fig. 2).

Occlusion of the blood flow to other tissues carried out in a similar manner by applying clips to the anterior mesenteric artery, left uterine artery or splenic artery did not cause a pressor response upon re-establishment of the circulation. In these cases a persistent but small fall in blood pressure was observed.

\section{Identification of pressor substances}

Blood samples taken from the renal vein immediately after clip release and incubated at room temperature for $10 \mathrm{~min}$ caused a contraction of the isolated superfused rat colon preparation but were without effect on the isolated guinea-pig ileum or rat gastric fundus strip. Similar samples taken before the release of the

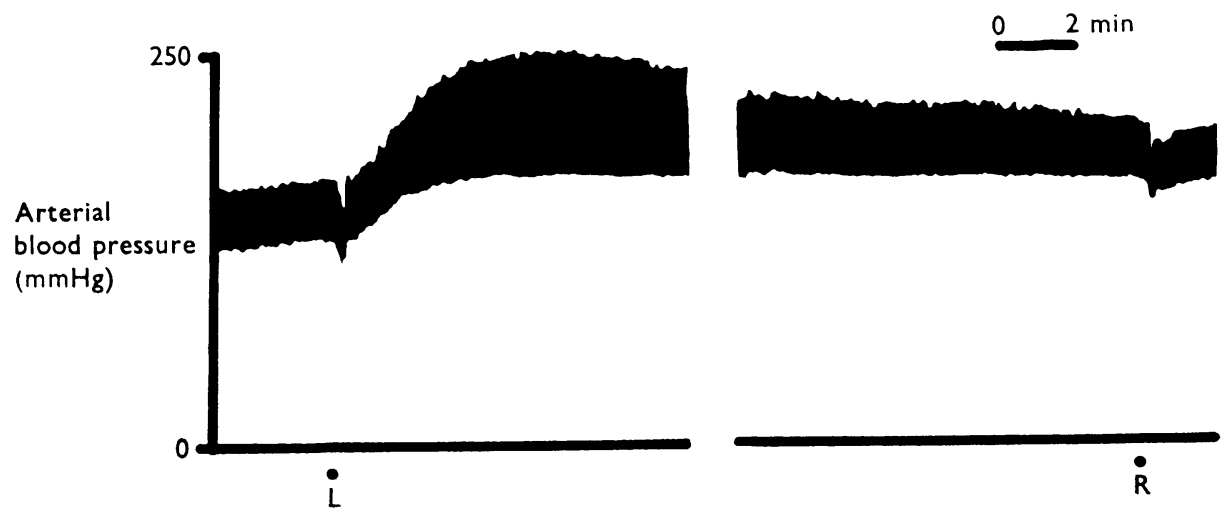

b

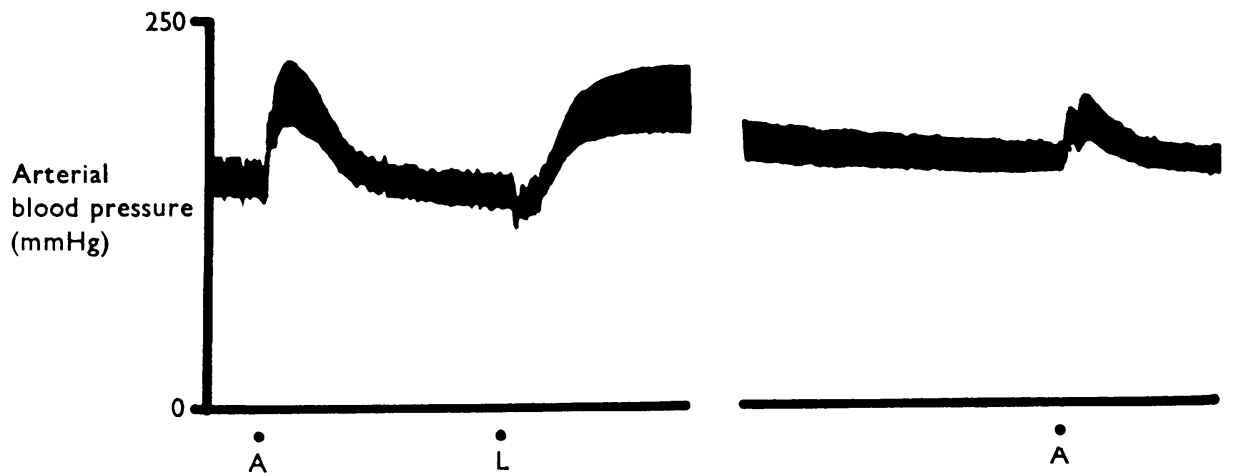

FIG. 2. Tachyphylaxis after renal pedicle clip release in anaesthetized rats. (a). To release of contralateral clip and (b). to intravenous injection of angiotensin. Release of left renal pedicle clip (L); release of right renal pedicle clip $(\mathrm{R})$; injection of angiotensin-II amide, $0 \cdot 5 \mu \mathrm{g}(\mathrm{A})$. 
clip were without effect on any of these preparations. The contraction of the rat colon was usually slightly less than that resulting from a concentration of val-5angiotensin II amide of $2.5 \mathrm{ng} / \mathrm{ml}$ although in one experiment it was similar to that given by $8 \mathrm{ng} / \mathrm{ml}$ (Fig. 3). Because of the difficulty of taking repeated blood samples the blood was monitored continuously in later experiments. In these experiments similar results were obtained (Fig. 4). Upon release of the clip the blood pressure rose and the tone of the rat colon increased. In some experiments there was also a slight increase in tone of the rat stomach strip but in no case was there any effect on the chick rectum. These results are consistent with the presence of angiotensin II in the superfusing blood but indicate the absence of significant quantities of catecholamines or prostaglandins.

\section{Effects of section of the spinal cord}

Contrary to expectations, re-establishment of the renal circulation in spinal rats or spinal cats did not result in any significant changes in blood pressure. The pressor response was abolished by transection of the spinal cord at all levels rostral to thoracic I (Fig. 5). Spinal transection in the thoracic region modified the response, the rise in blood pressure being more gradual. Spinal transection between thoracic 13 and lumbar 1 or more caudad had no detectable effect on the pressor response (Fig. 5).

Blood samples taken from spinal animals (transection between the skull and the atlas and the brain destroyed) before removal of the renal pedicle clip did not contain detectable quantities of angiotensin II. Samples taken from spinal animals after clip removal were qualitatively indistinguishable from samples taken from intact anaesthetized preparations (Fig. 3). Continuous monitoring of blood from spinal rat preparations in which the contralateral kidney had been removed did not, however, show evidence of the release of renin, there being no effect on any of the superfused organs (Fig. 4).

\section{Effect of autonomic blockade}

The effects of spinal transection in the thoracic region suggested that sympathetic reflex pathways were involved in the mediation of the pressor response. Neither

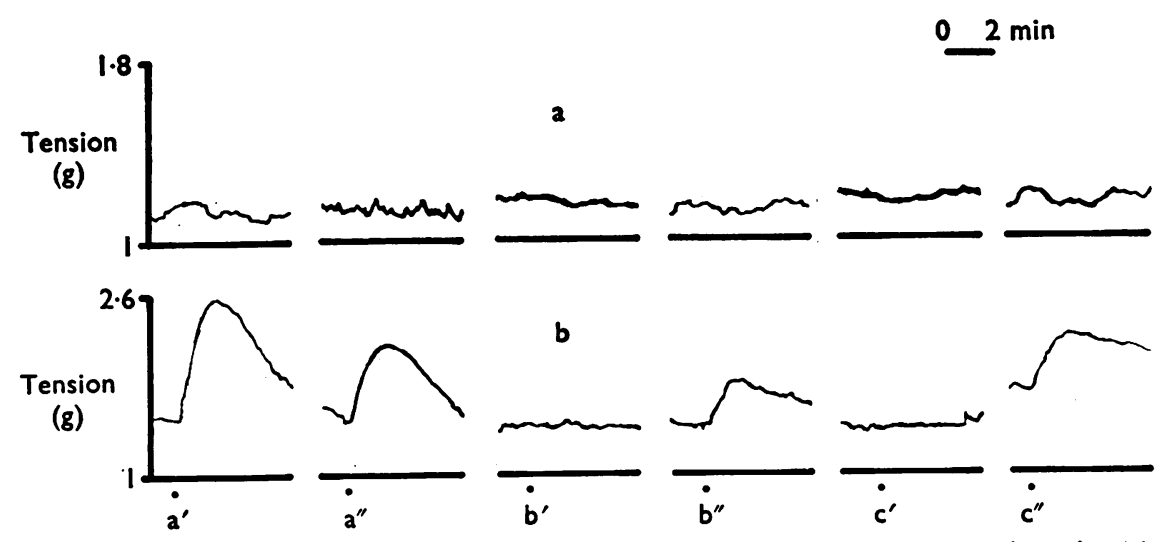

FIG. 3. Effects of $0 \cdot 1 \mathrm{ml}$ blood samples on isolated superfused rat stomach strip (a) and FIG. 3. Effects of $0.1 \mathrm{ml}$. Samples containing angiotensin-II amide, $1 \mathrm{ng}\left(\mathrm{a}^{\prime}\right)$ and $0.5 \mathrm{ng}\left(\mathrm{a}^{\prime \prime}\right)$; samples from pentobarbitone anaesthetized rats before release of left renal pedicle clip ( $\left.b^{\prime}\right)$ and $1 \mathrm{~min}$ after clip release $\left(b^{\prime \prime}\right)$; sample from spinal rat before left renal pedicle clip release $\left(c^{\prime}\right)$ and after clip release $\left(c^{\prime \prime}\right)$. 
bilateral adrenalectomy nor bilateral vagotomy and ganglion blockade with hexamethonium bromide, $5 \mathrm{mg} / \mathrm{kg}$ intravenously, abolished or diminished the response, whereas bilateral stellate ganglionectomy caused a total inhibition of the pressor response (Fig. 6).

\section{Discussion}

The observations of Lewis, Leo \& Prinzmetal (1941) that re-establishment of the renal circulation after several hours ischaemia results in a pressor response in rats
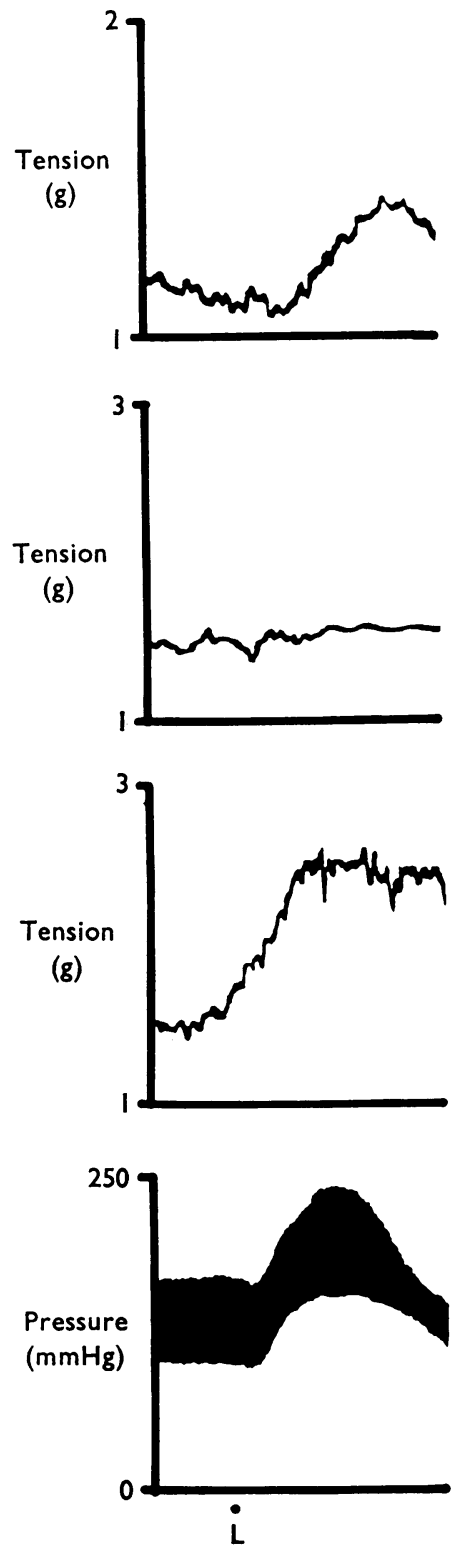

Anaesthetized rat a

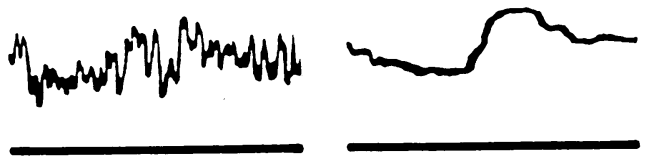

b
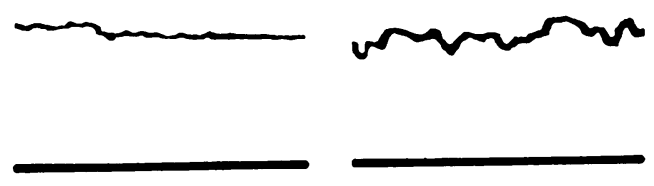

c
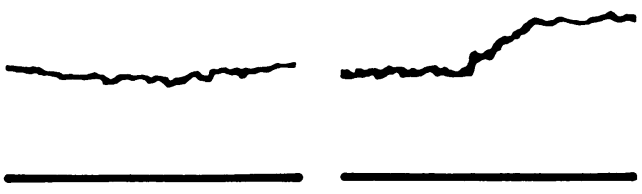

d
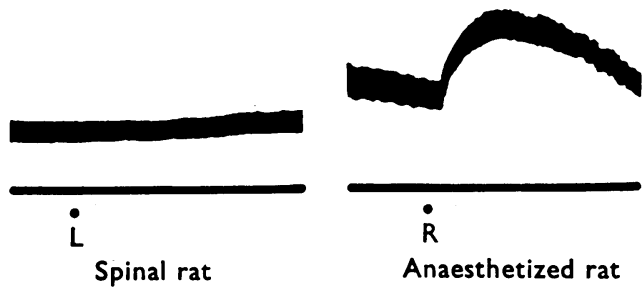

FIG. 4. Continuous monitoring of blood on blood bathed organs after release of left renal pedicle clip (L) or intravenous injection of rat renin (R). (a), Rat stomach strip ; (b), chick rectum; (c), rat colon; (d), rat arterial blood pressure. 
and cats have been confirmed. Failure to produce the effect by occlusion of the renal vein alone is in agreement with the results of other workers (Lowe, 1964 ; Vander \& Miller, 1964 ; McKenzie, Cook \& Lee, 1966) and confirms that it is a reduction in renal arterial blood pressure rather than ischaemia which results in the release of a pressor substance. That the pressor response results from the release
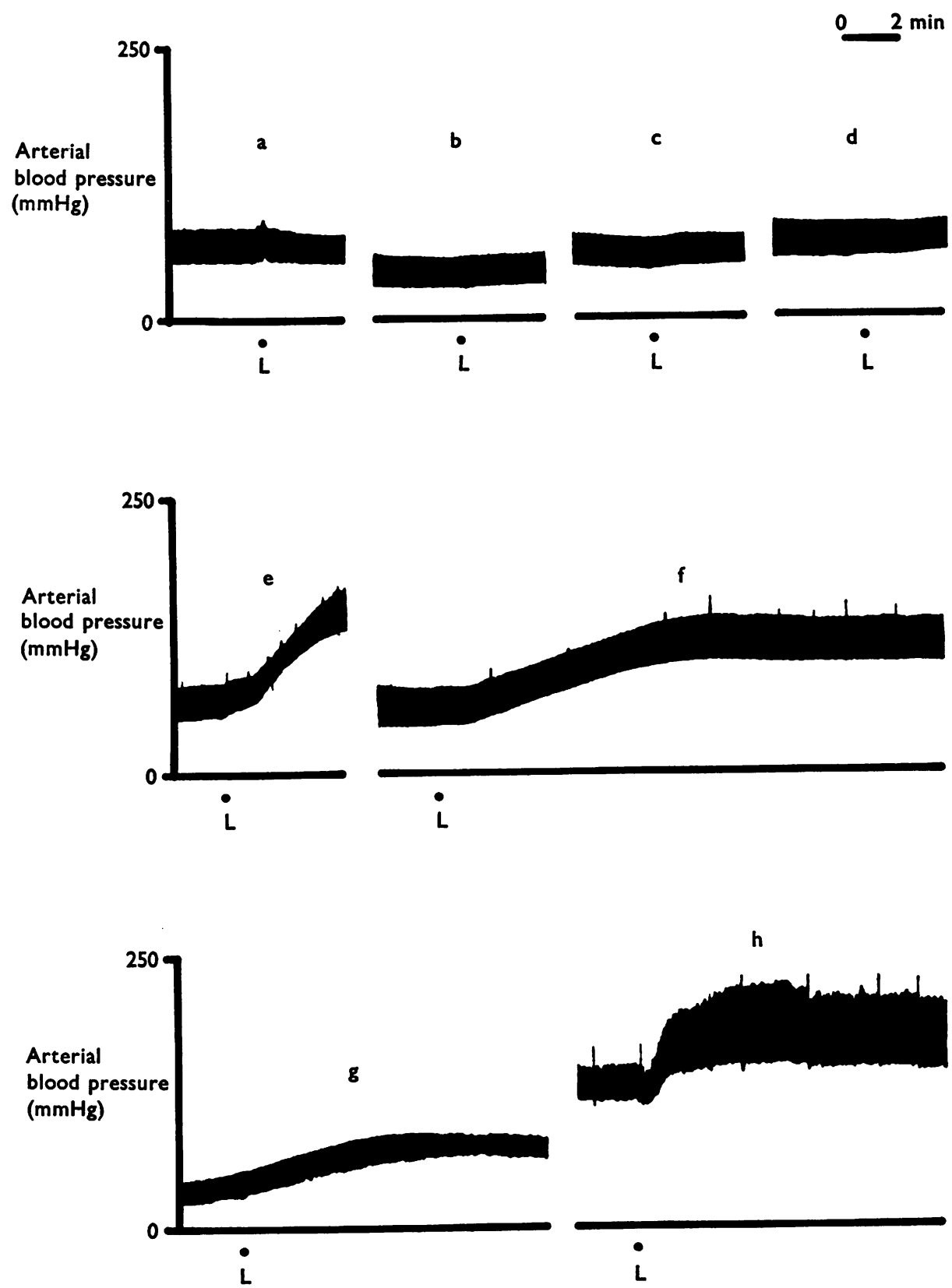

FIG. 5. Effects of release of left renal pedicle clip (L) on blood pressure of anaesthetized rats after total destruction of brain (a); spinal transection between skull and atlas (b); C6 and C7, (c); C7 and T1, (d); T1 and T2, (e); T2 and T3, (f); T8 and T9, (g); and T13 and L1, (h). 
of renin after re-establishment of the circulation was demonstrated by the identification of angiotensin in the blood and by the occurrence of tachyphylaxis to angiotensin II.

The spinal rat preparation is at least as sensitive to angiotensin as the anaesthetized preparation (Finch \& Leach, 1969). It was quite unexpected to find that section of the spinal cord in both rats and cats abolished the response. It therefore seemed probable that no renin was being released in these preparations. Analysis of blood samples taken after the re-establishment of the circulation in spinal animals using the isolated superfused rat stomach strip, guinea-pig ileum and rat colon did, however, show the presence of angiotensin. When these experiments were repeated using continuous monitoring of the blood on blood bathed organs, no angiotensin-like activity was detected in the spinal animal although such activity was detectable in the intact anaesthetized preparations. It is therefore apparent that although some renin was released in the spinal preparation, the quantity was too small to produce sufficient angiotensin to cause a pressor response. Prolonged incubation of a sample of such blood would permit the accumulation of detectable quantities of angiotensin.

It is likely that the release of renin is controlled by more than one mechanism (Lee, 1969) and that mutual interaction between these mechanisms is responsible for the maintenance of a normal level. These mechanisms are the renal baroreceptor mechanism, the sympathetic nervous mechanism and the macula densa mechanism (Goormaghtigh, 1944). The reduction in renin release after spinal section at cervical and thoracic levels suggests that in this case the sympathetic nervous mechanism is being interrupted and this is further confirmed by the similar effects of stellate ganglionectomy, although this latter effect has not yet been confirmed by estimation of renin release. The failure of ganglion blockade with hexamethonium bromide to affect the pressor response has not, however, been explained and is at variance with this hypothesis.

Furthermore, if renin were released as a result of a purely local mechanism such as either the renal baroreceptor or macula densa mechanism then the re-establishment of the renal circulation would merely release into the general circulation the renin already released into the renal vasculature during the period of ischaemia. In this case spinal transection would not have been expected to have any effect since the section was not effected until 10-15 $\mathrm{min}$ before the re-establishment of the circulation and therefore the period of renal ischaemia with an intact nervous system was similar for both intact and spinal preparations.

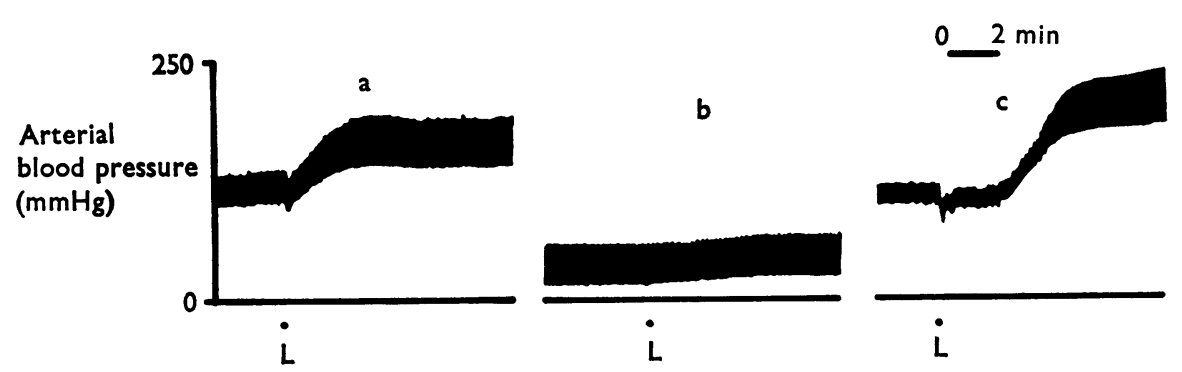

FIG. 6. Responses of arterial blood pressure to release of left renal pedicle clip (L) in anaesthetized rats after bilateral adrenalectomy (a); stellate ganglionectomy (b) ; or bilateral vagotomy and treatment with hexamethonium bromide, $5 \mathrm{mg} / \mathrm{kg}$ intravenously, (c). 
Although both anaesthetized and spinal rats are very sensitive to intravenous injections of angiotensin II recent evidence for central mediation of the pressor effect of angiotensin II suggests that concentrations which are ineffective when given intravenously may be effective when given by other routes. Ferrario et al. (1969) describe a pressor response to infusions of $1-12(\mathrm{ng} / \mathrm{kg}) / \mathrm{min}$ into the vertebral arteries of dogs although similar infusions into a carotid artery or intravenously were without effect. It is possible that the pressor effect resulting from the intravenous injection of angiotensin II is produced by a mechanism different from that causing the pressor response to angiotensin II formed by circulating renin. Spinal transection enhances rather than inhibits the pressor response to intravenous injection of angiotensin II but would destroy the mechanism of the centrally mediated response described by Ferrario et al. (1969) which is possibly the more important effect produced by angiotensin II formed by circulating renin.

The direct stimulant actions of angiotensin II on the superior cervical ganglion (Lewis \& Reit, 1965) and on the stellate ganglion (Aiken \& Reit, 1968) may also be involved in the production of the pressor response. These actions were shown to occur in spinal preparations and thus cannot in any way explain the failure of spinal rats to produce a pressor response to re-establishment of the renal circulation after ischaemia. The total inhibition of the pressor response caused by stellate ganglionectomy in the otherwise intact preparation may be explained at least in part by the removal of this mechanism.

The failure of the spinal rat to produce a pressor response to re-establishment of blood flow through an ischaemic kidney is probably the result of interference with more than one mechanism. First, the central component of the pressor response to angiotensin is removed and second, it is clear that the neural release of renin is inhibited; and although some renin may be released by either a renal baroreceptor or a macula densa mechanism it is insufficient to form enough angiotensin to cause a peripherally mediated pressor response. Further quantitative investigations of these mechanisms together with the use of autonomic nervous system inhibiting drugs and the identification of those areas of the brain which are essential to the mediation of the response are in progress in order to define more precisely the reasons why spinal transection abolishes the pressor response to re-establishment of the circulation in ischaemic kidneys.

The authors wish to acknowledge the skilled technical assistance of Mrs. J. A. Tubby and Mr. I. L. West.

\section{REFERENCES}

AIKEN, J. W. \& ReIT, E. (1968). Stimulation of the cat stellate ganglion by angiotensin. J. Pharmac exp. Ther., 159, 107-114.

Benelli, G., Della Bella, D. \& Gandini, A. (1964). Angiotensin and peripheral sympathetic nerve activity. Br. J. Pharmac. Chemother., 22, 211-219.

Buckley, J. P., Bickerton, R. K., Halliday, R. P. \& Kato, R. (1963). Central effects of peptides on the cardiovascular system. Ann. N.Y. Acad. Sci., 104, 299-311.

Distler, A., Liebau, H. \& WolfF, H. P. (1965). Action of angiotensin on sympathetic nerve endings in isolated blood vessels. Nature, Lond., 207, 764-765.

FeldBerG, W. \& Lewis, G. P. (1964). The action of peptides on the adrenal medulla. Release of adrenaline by bradykinin and angiotensin. J. Physiol., London., 171, 98-108.

Ferrario, C. M., Dickinson, C. J., Gildenberg, P. L. \& McCubbin, J. W. (1969). Central vasomotor stimulation by angiotensin. Fedn Proc., 28, 768.

FinCH, L. \& LEACH, G. D. H. (1969). The role of the sympathetic nervous system in the cardiovascular responses to angiotensin in the pithed rat. Br. J. Pharmac., 36, 481-488.

Goormaghtigh, N. (1964). La fonction endocrine des arterioles renales. Louvain. Libraire Fonteyn. 
Haas, E., Goldblatt, H., Gipson, E. C. \& Lewis, L. (1966). Fraction, purification and assay of human renin free of angiotensinase. Circulation Res., 19, 739-749.

Laverty, R. (1963). A nervously mediated effect of angiotensin in anaesthetized rats. J. Pharm. Pharmac., 15, 63-68.

LeE, M. R. (1969). Renin and Hypertension. A Modern Synthesis. London: Lloyd-Luke.

Lewis, J. A., Leo, S. D. \& Prinzmetal, M. (1941). The effect of re-establishment of circulation in completely ischaemic kidneys upon the blood pressure of cats, dogs and rats. Am. Heart J., 21, 319-325.

LEWIS, G. P. \& ReIT, E. (1965). The action of angiotensin and bradykinin on the superior cervical ganglion of the cat. J. Physiol., Lond., 179, 538-553.

LowE, R. D. (1964). Factors concerning the release of renin from the kidney. Lancet, 2, 183-185.

McCubbin, J. W. \& Page, I. H. (1963). Renal pressor system and neurogenic control of arterial pressure. Circulation Res., 12, 553-559.

McKenzie, J. K., CoOK, W. F. \& LeE, M. R. (1966). Effect of haemorrhage on arterial plasma renin activity in the rabbit. Circulation Res., 19, 269-273.

Page, I. H. \& Bumpus, F. M. (1961). Angiotensin. Physiol. Rev., 41, 331-390.

Prinzmetal, M., Lewis, H. A., Taggart, J., Wilkins, H. \& Drury, D. R. (1940). The effect of transplanted ischaemic kidneys and of temporary, complete, renal ischaemia upon the blood pressure of rabbits. Am. Heart J., 20, 525-538.

Regoli, D. \& VANE, J. R. (1964). A sensitive method for the assay of angiotensin. Br. J. Pharmac. Chemother., 23, 351-359.

Scroop, G. C. \& Lowe, R. D. (1968). Central pressor effect of angiotensin mediated by the parasympathetic nervous system. Nature, Lond., 220, 1331-1332.

Scroop, G. C. \& Whelan, R. F. (1966). A central vasomotor action of angiotensin in man. $J$. Clin. Sci., 30, 79-90.

TAQUini, A. C. (1938). Liberaction de substancia hipertensora en el rinon completemente isquemiado. Revta. Soc. Argent. Biol., 14, 422-428.

Vander, A. J. \& Miller, R. (1964). Control of renin secretion in the anaesthetized dog. Am. J. Physiol., 207, 537-546.

VAne, J. R. (1969). The release and fate of vaso-active hormones in the circulation. Br. J. Pharmac. 35, 209-242.

(Received October 9, 1970) 